\title{
A COMPARISON OF THE MERCURIAL DIURETICS USED IN HEART FAILURE
}

\author{
BY \\ WILLIAM EVANS AND THOMAS PAXON \\ From the Cardiac Department of the London Hospital \\ Received March 11, 1941
}

Digitalis is without equal in the treatment of heart failure in mitral stenosis with auricular fibrillation, though diuretics may also be needed. But when heart failure occurs with normal rhythm, as in hypertension, mercurial diuretics usually prove more successful than digitalis in increasing the urinary output, in lessening pulmonary congestion, and in relieving dyspnœa. Since the circumstances that demand the use of diuretics are known, it is necessary to learn which preparation is best to prescribe, in what form to give it, and how best to improve upon its own diuretic effect.

The object of this paper is to provide answers to these inquiries, and to continue the investigations carried out in the Cardiac Department of the London Hospital by Thomson (1937). It gives the results of a clinical trial in which selected mercurial preparations were administered in various ways after different methods of premedication.

\section{The InVestigation Described}

Fifty patients with heart failure, 30 men and 20 women, were selected for this clinical trial. Hypertension was the cause of the failure in 28 , mitral stenosis in 12 , and other less common conditions in 10 cases. The need for mercurial diuretics was determined by finding evidence of fluid retention on clinical examination. In some patients with hypertensive heart failure, frank œedema could not be demonstrated, but the symptom of breathlessness and the X-ray appearance of pulmonary congestion gave proof of their suitability for this form of therapy. Each patient was admitted to hospital and confined to bed during the period of investigation. The fluid intake was recorded daily and it was usually restricted to 35 ounces. The daily urinary output was also recorded. For convenience in assessing the results of this investigation, we have referred to the excess of the daily output of urine over the fluid intake, both measured in ounces, as the diuretic index. Naturally this figure is less than zero in a patient in whom heart failure is progressing. If vomiting or diarrhœa occurred under observation this received due regard in the interpretation of results. In some of the patients, especially those with mitral stenosis and auricular fibrillation, digitalis had to be given, but its effects had become constant and standard 
before a mercurial diuretic was introduced, so that the results remain strictly comparable throughout periods of continued digitalization. The effect of a diminished fluid intake and of rest upon the urinary output was also kept in mind when the diuretic value of any medicine was being decided. The following preparations were submitted for clinical trial: esidrone, mersalyl, neptal, novurit, and salyrgan. Sometimes it was possible to try every preparation after different forms of premedication in the same patient, but more often it was only feasible to compare in a single patient either the preparations or the adjuvants. The preparations were given by intravenous or intramuscular injection in a dose of 2 c.c. by mouth, and by rectal suppository in the case of two preparations. The effects of 307 injections were observed, 197 intravenously and 110 intramuscularly.

\section{RESULTS}

An estimate of the diuretic property of drugs, based as it must be on a comparison of the quantity of urine passed following their administration in different patients, requires care in that there may be several variables. We have tried to eliminate these by making allowance for the extent of anasarca at the time each medicine was given; by comparing the diuretic effect of each drug, only when it had been given to the same patient following the same form of premedication; by varying the sequence with which the drugs were given, because the first diuretic response is usually greater than succeeding ones; and by taking into consideration the interval between each administration. The results are presented under three main headings, which deal with choice of preparations, method of administration, and premedication.

\section{Choice of Preparation}

Judgement of the relative diuretic power of esidrone (prepared by Ciba), mersalyl (B.P. 1936; the variety used in this investigation was prepared by British Drug Houses), neptal (prepared by May and Baker), and salyrgan (prepared by Bayer) was made by comparing the effects of intravenous injection only, following the same form of premedication.

These preparations, which all contain theophyllin as well as mercury, were tried in 15 patients to whom 30 grains $(2 \mathrm{~g}$.) of ammonium chloride had been given two hours before each injection. They were not given in the same rotation, so that if esidrone was used first in one patient it was given second in the next patient, and third and fourth in succeeding patients. Again, each preparation that was given first was repeated before the second preparation was tried. That this manœuvre was necessary was shown later when the diuresis produced by the first and second injections were compared in 27 patients: the first injection induced greater diuresis than the second in 22 , and the average diuretic index for the 27 patients was 72 for the first injection and 49 for the second.

The actual diuresis induced in each of the 15 patients by the four preparations is shown in Table I, and an analysis of these results is given in Table II. From 
these data it will be seen that neptal and esidrone proved more efficient than salyrgan and that this were more efficient than mersalyl.

TABLE I

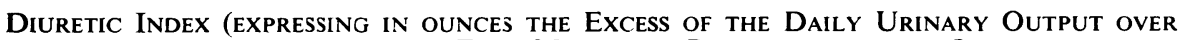
the Fluid Intake) Produced by Four Mercurial Preparations given Intravenously

\begin{tabular}{|c|c|c|c|c|c|c|c|c|}
\hline \multirow{2}{*}{ Case No. } & \multicolumn{2}{|c|}{ Esidrone } & \multicolumn{2}{|c|}{ Mersalyl } & \multicolumn{2}{|c|}{ Neptal } & \multicolumn{2}{|c|}{ Salyrgan } \\
\hline & $\begin{array}{c}\text { Same } \\
\text { Day }\end{array}$ & $\begin{array}{l}\text { Next } \\
\text { Day }\end{array}$ & $\begin{array}{c}\text { Same } \\
\text { Day }\end{array}$ & $\begin{array}{l}\text { Next } \\
\text { Day }\end{array}$ & $\begin{array}{l}\text { Same } \\
\text { Day }\end{array}$ & $\begin{array}{l}\text { Next } \\
\text { Day }\end{array}$ & $\begin{array}{l}\text { Same } \\
\text { Day }\end{array}$ & $\begin{array}{l}\text { Next } \\
\text { Day }\end{array}$ \\
\hline $\begin{array}{r}3 \\
5 \\
6 \\
7 \\
8 \\
10 \\
11 \\
12 \\
13 \\
16 \\
17 \\
21 \\
22 \\
23 \\
24\end{array}$ & $\begin{array}{r}76 \\
67 \\
84 \\
67 \\
16 \\
53 \\
34 \\
58 \\
85 \\
43 \\
26 \\
62 \\
116 \\
48 \\
96\end{array}$ & $\begin{array}{r}0 \\
29 \\
-2 \\
-17 \\
44 \\
18 \\
-8 \\
35 \\
5 \\
-5 \\
2 \\
22 \\
10 \\
1 \\
9\end{array}$ & $\begin{array}{r}33 \\
58 \\
63 \\
49 \\
37 \\
55 \\
11 \\
69 \\
39 \\
39 \\
6 \\
65 \\
47 \\
49 \\
69\end{array}$ & $\begin{array}{r}-13 \\
11 \\
4 \\
-20 \\
10 \\
8 \\
-9 \\
40 \\
-11 \\
-19 \\
0 \\
10 \\
1 \\
12 \\
-6\end{array}$ & $\begin{array}{r}58 \\
62 \\
176 \\
52 \\
45 \\
83 \\
41 \\
26 \\
25 \\
51 \\
29 \\
67 \\
84 \\
57 \\
64\end{array}$ & $\begin{array}{r}-7 \\
5 \\
10 \\
-5 \\
26 \\
-1 \\
-7 \\
32 \\
-5 \\
-20 \\
-6 \\
12 \\
16 \\
5 \\
-19\end{array}$ & $\begin{array}{l}24 \\
86 \\
92 \\
57 \\
52 \\
83 \\
27 \\
76 \\
24 \\
13 \\
73 \\
26 \\
40 \\
70 \\
75\end{array}$ & $\begin{array}{r}7 \\
29 \\
8 \\
3 \\
5 \\
-4 \\
-4 \\
50 \\
0 \\
0 \\
-15 \\
-7 \\
-22 \\
-3 \\
-17\end{array}$ \\
\hline $\begin{array}{c}\text { Average } \\
\text { diuretic index }\end{array}$ & 62 & 9 & 46 & 1 & 61 & 2 & 54 & 1 \\
\hline
\end{tabular}

TABLE II

Relative Diuretic Potency of four Mercurial Preparations. The Numerals indicate the Positions gained by each Preparation in 15 Patients

\begin{tabular}{|c|c|c|c|c|c|c|}
\hline \multirow{2}{*}{\multicolumn{3}{|c|}{ Preparation }} & \multicolumn{4}{|c|}{ Relative Potency } \\
\hline & & & 1st Place & 2nd Place & 3rd Place & 4th Place \\
\hline $\begin{array}{l}\text { Esidrone } \\
\text { Mersalyl } \\
\text { Neptal } \\
\text { Salyrgan }\end{array}$ & $\begin{array}{l}\ldots \\
\ldots \\
\ldots \\
\ldots\end{array}$ & $\begin{array}{l}\ldots \\
\cdots \\
\ldots\end{array}$ & $\begin{array}{l}5 \\
0 \\
5 \\
5\end{array}$ & $\begin{array}{l}3 \\
3 \\
5 \\
4\end{array}$ & $\begin{array}{l}4 \\
7 \\
3 \\
1\end{array}$ & $\begin{array}{l}3 \\
5 \\
2 \\
5\end{array}$ \\
\hline
\end{tabular}

\section{Method of Administration}

Esidrone, mersalyl, neptal, and salyrgan were tried by intravenous and intramuscular injection. The diuretic effects of mersalyl, neptal, and salyrgan were also compared when given by mouth in tablet form. Novurit was tried as a rectal suppository and sometimes compared with salyrgan suppository. Naturally the diuresis produced by mercurial preparations when taken by mouth was not expected to equal that obtained by injection, so that the value of intramuscular and intravenous injections was compared first; and separately, the relative value of tablets given by mouth and of rectal suppositories. 


\section{Intravenous and Intramuscular Injection}

The effects of intravenous and intramuscular injections were observed on 15 occasions, always with similar premedication. Each of the four mercurial salts was included in this trial, and esidrone was given both by intravenous and intramuscular injection in 3 patients, mersalyl in 2, neptal in 5, and salyrgan in 5. The results are shown in Table III. The intravenous method induced greater

TABLE III

The Diuretic Index (eXPressing in OUNCes the Excess of THE Daily Urinary OutPut OVER THE FLUID INTAKE) OF INTRAVENOUS AND INTRAMUSCULAR INJECTIONS OF FOUR Mercurial Salts.

\begin{tabular}{|c|c|c|c|c|c|}
\hline \multirow{2}{*}{ Case No. } & \multirow{2}{*}{ Preparation } & \multicolumn{2}{|c|}{ Intravenous Injection } & \multicolumn{2}{|c|}{ Intramuscular Injection } \\
\hline & & Same Day & Next Day & Same Day & Next Day \\
\hline $\begin{array}{r}3 \\
4 \\
6 \\
7 \\
8 \\
10 \\
10 \\
12 \\
12 \\
18 \\
21 \\
22 \\
22 \\
23 \\
24\end{array}$ & $\begin{array}{l}\text { Esidrone } \\
\text { Salyrgan } \\
\text { Neptal } \\
\text { Salyrgan } \\
\text { Mersalyl } \\
\text { Neptal } \\
\text { Salyrgan } \\
\text { Neptal } \\
\text { Salyrgan } \\
\text { Salyrgan } \\
\text { Mersalyl } \\
\text { Esidrone } \\
\text { Neptal } \\
\text { Neptal } \\
\text { Esidrone }\end{array}$ & $\begin{array}{r}76 \\
73 \\
176 \\
57 \\
37 \\
83 \\
83 \\
26 \\
76 \\
32 \\
65 \\
116 \\
84 \\
57 \\
96\end{array}$ & $\begin{array}{r}0 \\
20 \\
10 \\
3 \\
10 \\
-1 \\
-4 \\
32 \\
50 \\
3 \\
10 \\
10 \\
16 \\
5 \\
9\end{array}$ & $\begin{array}{r}57 \\
40 \\
119 \\
48 \\
24 \\
69 \\
42 \\
58 \\
28 \\
62 \\
56 \\
87 \\
38 \\
47 \\
62\end{array}$ & $\begin{array}{r}14 \\
12 \\
1 \\
-8 \\
52 \\
2 \\
-6 \\
39 \\
38 \\
-11 \\
10 \\
21 \\
-13 \\
0 \\
-13\end{array}$ \\
\hline \multicolumn{2}{|c|}{ Average diuretic index } & 76 & 11 & 56 & 9 \\
\hline
\end{tabular}

diuresis on 13 out of 15 occasions, and this applied to each preparation. In one of two patients where intramuscular injection proved more efficient than intravenous injection this predominant effect was constant during further trials (Fig. 1). The average diuretic index was 76 for the first day and 11 for the second day for the intravenous injection and 56 and 9 for the intramuscular injection. The intravenous method was favoured by patients because they experienced greater pain from intramuscular injections.

\section{Oral and Rectal Administration}

The diuretic effects of tablets of mersalyl, neptal, and salyrgan, when taken by mouth, were observed during 68 separate trials with the same premedication. All the tablets contained $0.08 \mathrm{~g}$. of the mercurial salt and $0.04 \mathrm{~g}$. of theophyllin. Five different methods of administering them were adopted. Thus, always two hours after 30 grains ( $2 \mathrm{~g}$.) of ammonium chloride, the dose was 2, 4, 6, or 8 tablets as a single dose, or 2 tablets three times during the day. Six tablets $(0.48 \mathrm{~g}$.) and 4 tablets $(0.32 \mathrm{~g}$.) produced the best diuretic effect, and this was actually greater than that produced by 8 tablets $(0 \cdot 64 \mathrm{~g}$.). Mersalyl produced 


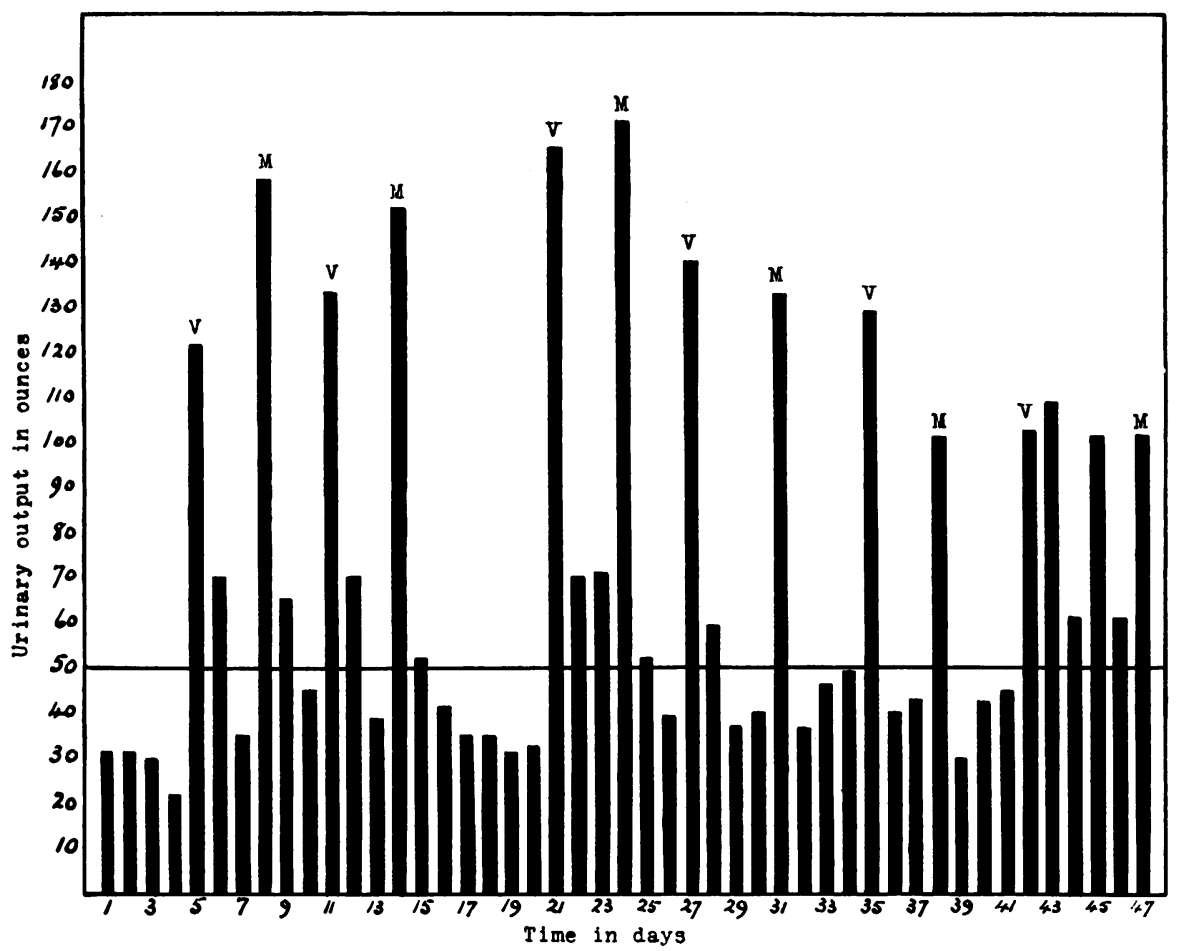

FIG. 1.-Comparison of the diuretic effects of intravenous and intramuscular injections of a mercurial salt in a patient with hypertensive heart failure. The daily fluid intake was kept constant at 50 ounces, and ammonium chloride (15 grains) was given three times daily. $V$, intravenous injection. $M$, intramuscular injection.

The superiority of intramuscular over intravenous injection was unusual.

satisfactory diuresis in 12 out of 19 trials and showed an average diuretic index of 19. Neptal tablets produced diuretic effects during each of 16 trials and the average diuretic index was 32 . Salyrgan tablets were successful in 13 out of 23 trials and had a diuretic index of 17. Diarrhœa was often occasioned by the tablets when they were taken three times daily but seldom when given as a single dose. Vomiting sometimes resulted from the mechanical effects of swallowing many tablets, for this symptom did not recur when the tablets were repeated. Thus, neptal tablets produced diuresis in a greater measure than mersalyl and salyrgan tablets. As a result of these trials the makers have decided to double the strength of neptal tablets in order to facilitate the correct dose; three tablets now contain $0.48 \mathrm{~g}$. of the mercurial salt and two tablets contain $0.32 \mathrm{~g}$.

Novurit, and sometimes salyrgan, was administered as a rectal suppository in 21 patients. In 8 there was no diuretic response, and the diuretic index for all cases was 17 . Novurit proved greatly superior to salyrgan suppository (Fig. 2). In 6 cases rectal irritation was produced. Premedication with euphyllin produced no better results than those obtained with ammonium chloride. When the diuretic effects of rectal and oral administration were compared the average diuretic index of 17 for the suppository was less than the 


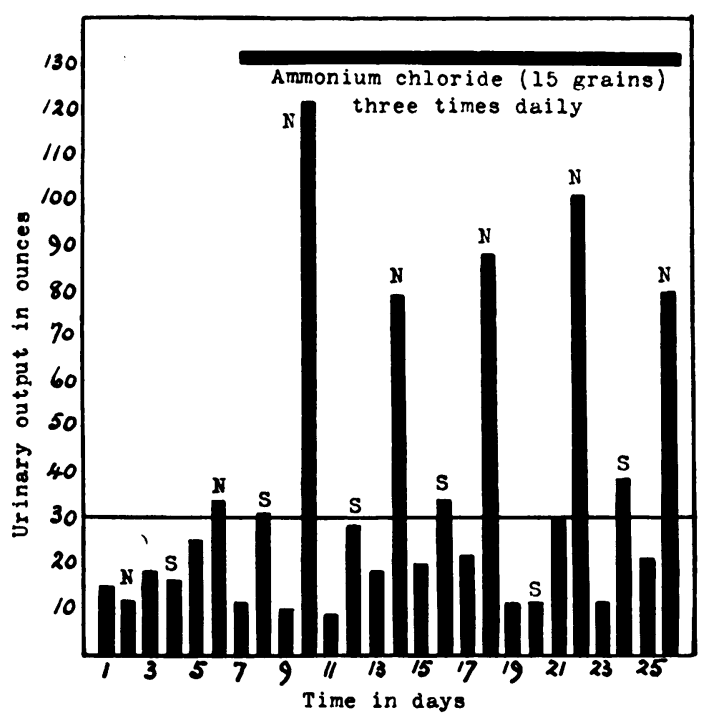

FIG. 2.-Comparing the diuresis produced by novurit and salyrgan suppositories, and showing the increased diuretic response following ammonium chloride in a patient with heart failure in mitral stenosis. The fluid intake was restricted to 30 ounces daily.

N, novurit suppository. S, salyrgan suppository.

22 for all tablets, and much less than the 32 for neptal tablets. The discomfort commonly associated with a rectal suppository gave oral administration another advantage. The value of oral administration of mercurial salts in the treatment of hypertensive heart failure is further illustrated in Fig. 3, where it is compared with other methods.

\section{Premedication}

The extent to which different methods of premedication amplified the diuresis naturally induced by mercurial salts was another subject of inquiry. Eleven different methods were tried, and in all 507 observations were recorded. When the efficiency of each form of premedication was under test the same mercurial salt was given to each patient, so that when the adjuvant preparation was varied the conditions remained constant. The following preparations and methods were tried: urea $(30 \mathrm{~g}$.) two hours before the mercurial salt; euphyllin $(0.4 \mathrm{~g}$.) two hours before; digoxin $(1 \mathrm{mg}$.) two hours before; vitamin $\mathrm{C}$ given continuously as 2 tablets of redoxon three times daily; and ammonium chloride (15 grains or $1 \mathrm{~g}$.) three times daily for one, two, or three days, or in doses of 15,45 , or 60 grains two hours before. These results were compared with those reached without premedication. Neither digoxin nor vitamin $\mathrm{C}$ proved constantly effective in increasing the diuresis produced by a mercurial salt. The other methods were invariably successful and their relative efficiency is shown in Table IV. Ammonium chloride is supplied by Eli Lilly, and by Evans, Lescher, and Webb, in the form of compressed enteric chocolate-coated tablets containing 7.5 grains $(0.5 \mathrm{~g}$.). The unpleasant salty taste is thereby avoided and these 


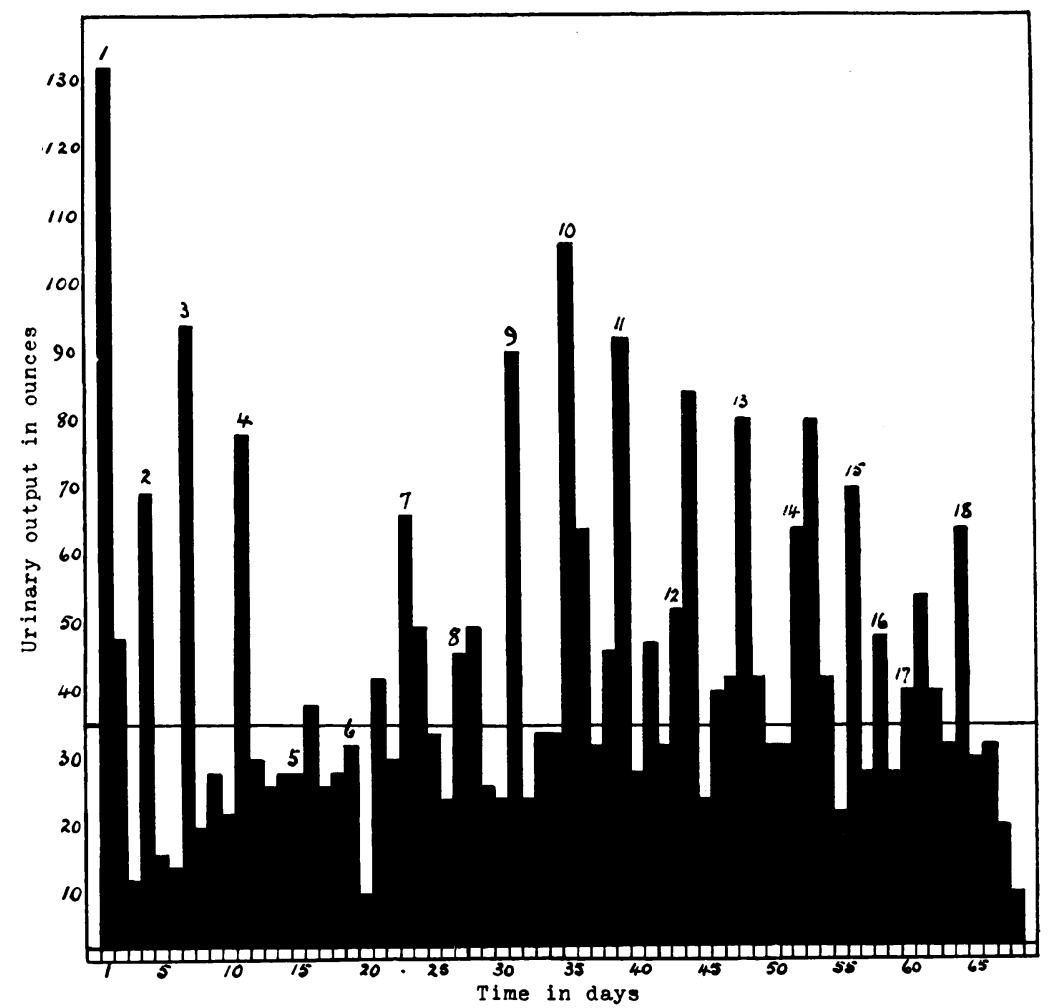

FIg. 3.-The diuresis produced by different mercurial preparations administered in different ways to a patient with hypertensive heart failure during ten weeks in hospital. Ammonium chloride ( 30 grains) was given two hours before each mercurial diuretic. The daily fluid intake was restricted to 35 ounces.

1. Salyrgan intravenously. 8. Salyrgan, six tablets.

2. Mersalyl intravenously. 9. Neptal, six tablets.

3. Neptal intravenously. 10. Neptal, eight tablets.

4. Esidrone intravenously. 11. Neptal intravenously.

5. Novurit suppository. 12. Neptal, two tablets, three

6. Novurit suppository. times during one day.

14. Neptal, two tablets, three times during one day.

15. Salyrgan, four tablets

16. Mersalyl, four tablets.

17. Mersalyl, six tablets.

7. Neptal, six tablets.

13. Neptal, six tablets.

18. Neptal, six tablets.

TABLE IV

The Relative Value of Different Methods of Premedication in augmenting the Natural Diuresis produced by a Mercurial Preparation

\begin{tabular}{|c|c|c|}
\hline $\begin{array}{l}\text { Order of } \\
\text { Efficiency }\end{array}$ & Method of Premedication & $\begin{array}{l}\text { Diuretic } \\
\text { Index }\end{array}$ \\
\hline $\begin{array}{l}1 \\
2\end{array}$ & $\begin{array}{l}\text { Ammonium chloride ( } 30 \text { grains or } 4 \text { tablets) two hours before } \\
\text { Ammonium chloride ( } 15 \text { grains or } 2 \text { tablets) three times a day for }\end{array}$ & 69 \\
\hline & three days $\ldots$ & 61 \\
\hline 3 & $\begin{array}{c}\text { Ammonium chloride (15 grains or } 2 \text { tablets) three times a day for } \\
\text { two days }\end{array}$ & 58 \\
\hline 4 & Urea $(30$ g.) two hours before & 57 \\
\hline 5 & Ammonium chloride ( 60 grains or 8 tablets) two hours before & 54 \\
\hline 6 & Ammonium chloride ( 45 grains or 6 tablets) two hours before & 53 \\
\hline $\begin{array}{l}7 \\
8\end{array}$ & $\begin{array}{l}\text { Euphyllin }(0.4 \mathrm{~g} .) \text { two hours before } \\
\text { Ammonium chloride }(15 \text { grains or } 2 \text { tablets) three times a day for }\end{array}$ & 49 \\
\hline & $\begin{array}{llllllllll}\text { one day } & \cdots & \ldots & \ldots & \ldots & \ldots & \ldots & \ldots & \ldots\end{array}$ & 39 \\
\hline 9 & Ammonium chloride ( 15 grains or 2 tablets) two hours before & 39 \\
\hline 10 & $\begin{array}{lllllll}\text { No premedication } & \ldots & \ldots & \ldots & \ldots & \ldots & \ldots\end{array}$ & 34 \\
\hline
\end{tabular}


tablets were used whenever ammonium chloride was prescribed. From the table it will be seen that 4 tablets ( 30 grains or $2 \mathrm{~g}$.) of ammonium chloride, taken by mouth two hours before the administration of a mercurial salt, proved the most efficient method of increasing its natural diuretic property.

\section{UNTOWARD EFFECTS}

No serious complications were encountered. Occasionally intramuscular injections, although given slowly, evoked local discomfort or even pain which lasted a variable time. Vomiting occurred sometimes when a number of tablets had to be taken, but this was not constant and during a second trial it might not recur. Diarrhcea usually resulted from the intake of a mercurial preparation by mouth three times daily. Rectal irritation, disagreeable, but never severe, affected one-third of the patients using a rectal suppository. Uramic symptoms were seen once in a woman, aged 56, with hypertensive heart failure (Case 38). Slight albuminuria was present when she was admitted to hospital, but there was no evidence of renal failure and the blood urea was normal. Salyrgan was given every third day, alternately by intravenous and intramuscular injection, over a period of 50 days, during which ammonium chloride (15 grains three times daily) had been given continuously. On the fiftieth day the patient was taken ill with weakness, anorexia, vomiting, listlessness, drowsiness, and dryness of the mouth and tongue. Ammonium chloride and salyrgan were discontinued and the fluid intake was increased. Within five days the patient became free from symptoms. Over a period of fourteen days after stopping the drugs the following blood urea values were obtained: $178,225,115,109,90$, and $60 \mathrm{mg}$. per 100 c.c. After three months, breathlessness returned and there was further need of treatment with mercurial diuretics; these were given following ammonium chloride premedication once a week during the following twelve months with freedom from symptoms of failure and without the advent of uræmic symptoms. As this single experience came to us early in the investigation the blood urea was estimated at least three times in the rest of the series. The first estimate was made before the investigation began, the second during the investigation, and the third towards the end. In none was the blood urea content raised significantly during treatment.

\section{CONCLUSIONS}

Certain mercurial diuretics were submitted to a clinical trial in 50 patients with heart failure, for the purpose of deciding their relative diuretic potency. The best method of administering them was also investigated, as well as the best means of augmenting their natural diuretic action. Esidrone, mersalyl, neptal, and salyrgan were given in 2 c.c. doses intravenously (197 times) and intramuscularly (110 times). Mersalyl, neptal, and salyrgan were tried orally in tablet form, and novurit and salyrgan were tested as a rectal suppository. Eleven methods of enhancing the diuretic effects of mercurial salts were also tested, and 507 observations were devoted to this problem. The results of this investigation are as follows:

1. Neptal and esidrone when given intravenously or intramuscularly pro- 
duced the largest diuresis, rather larger than salyrgan and much larger than mersalyl.

2. The intravenous method almost always induced greater diuresis (average diuretic index of 76 ) than the intramuscular method (average diuretic index of 56).

3. Of the two rectal suppositories tried, novurit gave much better results than salyrgan.

4. Neptal tablets by mouth proved more efficient (average diuretic index of 32) than mersalyl tablets (average diuretic index of 19), salyrgan tablets, or novurit suppositories rectally (each with a diuretic index of 17). Ammonium chloride was always given in association.

5. Although the urinary output after oral administration of a mercurial salt was greatest when $0.48 \mathrm{~g}$. ( 3 new tablets) of neptal were used, satisfactory diuresis was also produced by $0 \cdot 32 \mathrm{~g}$. ( 2 new tablets).

6. Thirty grains $(2 \mathrm{~g}$.) of ammonium chloride given two hours before the administration of a mercurial preparation proved to be the best form of premedication. Enteric chocolate-coated tablets, each containing 7.5 grains $(0.5 \mathrm{~g}$.), proved the most convenient form of dispensing ammonium chloride.

7. In a patient confined to bed with heart failure and especially with œdema, standard treatment would include the injection of a mercurial diuretic ( 2 c.c.) intravenously or intramuscularly every third day, preceded on each occasion by the administration of 4 tablets ( 30 grains or $2 \mathrm{~g}$.) of ammonium chloride by mouth two hours before. During the ambulatory stage the patient should take neptal tablets ( 3 in all, or $0.48 \mathrm{~g}$.), twice weekly in the more severe case and once a week in the less severe case, after the same premedication, and receive an intravenous or intramuscular injection ( 2 c.c.) at intervals according to need.

We wish to thank Dr. John Parkinson, Physician to the Cardiac Department of the London Hospital, for his helpful criticism of this paper. Dr. P. T. Savage joined in the investigation when he was House Physician to the Department. We acknowledge the able co-operation so loyally given to us by Sisters in charge of the wards. Mr. C. H. Sykes, Ph.C., Chief Pharmacist to the Hospital, has given us great assistance.

\section{REFERENCE}

Thomson, W. A. R. (1937). Quart. J. Med., 30, 321. 